\title{
Cultural landscapes of the future: using agent-based modeling to discuss and develop the use and management of the cultural landscape of South West Devon
}

\author{
Koen F. Tieskens $\cdot$ Brian J. Shaw $\cdot$ Toon Haer • \\ Catharina J. E. Schulp • Peter H. Verburg
}

Received: 22 September 2016/Accepted: 2 March 2017/Published online: 16 March 2017

(C) The Author(s) 2017. This article is an open access publication

\begin{abstract}
Context Hedgerows are typical landscape features of high environmental and cultural value that often have been sacrificed for agricultural intensification and scale enlargement.

Objectives We studied the dynamics of hedgerow quality over time in a case study area renowned for its hedgerow landscapes: South West Devon (UK) answering the following research questions: (1) how does the imperative of scale enlargement affect hedgerow quality? and (2) to what extent can cultural
\end{abstract}

Electronic supplementary material The online version of this article (doi:10.1007/s10980-017-0502-2) contains supplementary material, which is available to authorized users.

K. F. Tieskens $(\varangle) \cdot$ T. Haer · C. J. E. Schulp ·

P. H. Verburg

Faculty of Earth and Life Sciences, VU University

Amsterdam, De Boelelaan 1087, 1081HV Amsterdam,

The Netherlands

e-mail: Koen.tieskens@vu.nl

B. J. Shaw

Chair for Landscape Management, Institute of Earth and Environmental Sciences, University of Freiburg,

79085 Freiburg, Germany

P. H. Verburg

Research Unit Landscape Dynamics, Swiss Federal

Research Institute WSL, Zürcherstrasse 111,

8903 Birmensdorf, Switzerland landscape degradation be countered by targeted policies?

Methods We applied an agent-based modeling approach, parameterized with a site specific survey, to explore and discuss outcomes of future landscape change with stakeholders and co-designed preferred scenarios of landscape change during a workshop.

Results Outcomes suggested that in the case-study area, scale enlargement has a negative effect on hedgerow quality when agri-environment scheme subsidies (AES) are low. In contrast, if the level of AES enrollment is high, scale enlargement can have a positive effect on hedgerow quality, as large holders are more likely to enroll for AES. Stakeholders acknowledged the need for agricultural intensification, but at the same time valued biodiversity and environmental value of the landscape in South West Devon.

Conclusion Current AES are able to retain a decent hedgerow quality. With lower AES, scale enlargement can have an invigorative effect on hedgerow quality as land managers of larger farms will be less likely to join AES As an addition to AES, harvesting wood fuel from coppiced hedgerows appears a promising way to incentivize rejuvenating hedgerow management without governmental subsidies.

Keywords Stakeholder engagement - Agent-based modeling · Land use change $\cdot$ Hedgerow quality $\cdot$ Joint learning $\cdot$ Agri-environment schemes 


\section{Introduction}

Over the past few decades, trends in land management, such as scale enlargement, agricultural intensification and land abandonment, have dramatically altered landscapes throughout Europe. Yet despite these changes, Europe still contains landscapes that have managed to retain a traditional small-scale character. Landscapes such as the French Bocage and the Tuscan valleys are attributed special cultural values (Tieskens et al. 2017) and host large amounts of biodiversity. However, current drivers of landscape change, such as an increasing demand for agricultural produce, urbanization, and climate change, can have a devastating effect on these traditional landscapes (Plieninger and Bieling 2013). Scale enlargement of farm holdings is another threat to cultural landscapes. Traditional land managers often have difficulties remaining commercially viable all around Europe. The United Kingdom (UK) is no exception to this trend. In the UK, between 2005 and 2014 the total number of commercial agricultural holdings dropped by more than $20 \%$, but the total area of agricultural area remained stable. A clear trend of scale enlargement is visible where small farms are abolished while large farms are getting larger in both size as well as numbers (DEFRA 2015). Although intensification and scale enlargement can increase commodity production, it often comes at the expense of biodiversity and cultural values of the landscape (Plieninger and Bieling 2012).

A typical case of a landscape that has retained its traditional small-scale character, but is now facing scale enlargement, is South West Devon, UK, an area characterized by mixed agricultural systems of pastures, arable fields and woodlands. Devon is often hailed as the quintessential example of a traditional British cultural landscape, featuring small pastoral fields bounded by the iconic British hedgerows. The hedgerows form a deeply rooted cultural value of the English Rural character (Fukamachi et al. 2003). Among both farmers and conservationists there is the common understanding that hedgerows are part of the national identity, creating a sense of place (Oreszczyn and Lane 2000). Hedgerows are also valued as a key habitat for a wide range of wildlife species that could otherwise not exist on intensively managed agricultural land (Staley et al. 2013).
Examples are the dormouse (Davies and Pullin 2007) and grey partridges (Rands 1986), but also a variety of lesser known invertebrates (Hannon and Sisk 2009) and plant species (Hinsley and Bellamy 2000).

Traditional landscape features such as hedgerows are threatened by the imperative of intensification and scale enlargement (Van der Zanden et al. 2013). Although regulations explicitly forbid removal, the total length of hedgerows in the UK declined with $6 \%$ from 1998 to 2007, mainly due to under-management (Carey et al. 2008). Furthermore, annual mechanized flail cutting as the main form of hedgerow management on modern intensive agricultural farms decreases the hedgerow quality, making them less suitable as a wildlife habitat (Hinsley and Bellamy 2000; Facey et al. 2014). Alternatively, wildlife friendly forms of management are labor intensive and require traditional skills that are no longer common amongst land managers (Staley et al. 2015). In many European countries, agri-environmental schemes (AES) were introduced providing financial incentives to land managers to apply environmentally sensitive management, in an attempt to restore or preserve landscape features such as hedgerows (Fuentes-Montemayor et al. 2011).

In this study, we explore how the changing rural population and shifts of interests due to scale enlargement can have an effect on the hedgerow quality in South West Devon. Moreover we explore different policy options to counter landscape degradation. We used an agent-based model (ABM) to translate the findings of a survey among land managers into a spatial representation of future hedgerow quality scenarios. We applied a participatory approach engaging local stakeholders to actively participate in the construction of the model and in discussing its outcomes. The outcomes of this study are therefore the result of negotiation and co-design with stakeholders, rather than a top-down scientific prediction and prescription of the societal issue of landscape degradation. We aimed to answer the following research questions: (1) how do the changing rural population and shifts of interests due to scale enlargement affect hedgerow quality? and (2) to what extent can landscape degradation be countered by targeted policies? 


\section{South West Devon}

South West Devon, also known as the South Hams, is a region where, due to its pastoral character, many hedgerows have persisted during the twentieth century (Barr and Gillespie 2000). South West Devon stretches from the fringes of Plymouth on the west to Torquay on the east. It includes parts of the Dartmoor National Park and is bounded by the coastline on the South (Fig. 1). For this study we excluded Dartmoor National Park as it forms an exceptional landscape requiring a different approach. South West Devon is inhabited by 84,500 people (Devon County Council 2016). Of all the land in South West Devon $90 \%$ is used for agriculture, mostly dairy farms and grazing livestock, with some patches of arable land. Devon is mostly characterized by medium sized (between 5 and $100 \mathrm{ha}$ ) farms compared to the rest of England (DEFRA 2015).

Very small ( $<5$ ha) and large farms ( $>100$ ha) are growing in numbers, while medium sized farms are declining (DEFRA 2015). The number of medium sized farms dropped from 8764 in 1995 to 5665 in 2013 while the number of large farms increased from 951 to 1617 (DEFRA 2015). The area occupied by large farms increased to almost $60 \%$ of the total agricultural land in 2013. At the same time, Devon is becoming a popular destination for second home buyers. The attraction of the Devon rural lifestyle caused an increase in the number of so called lifestyle farmers. Lifestyle farmers are mostly retired urbanites with a small patch of land where they keep some livestock and grow vegetables for non-commercial use.

AES are part of the European-wide Common Agricultural Policy and were installed in 1980 throughout Europe to enhance environmental value of agricultural ecosystems with individual farm level subsidies. AES usually provide financial incentives to farmers to comply with environmentally sensitive management prescriptions to enhance the ecological value of agricultural ecosystems such as hedgerows. In

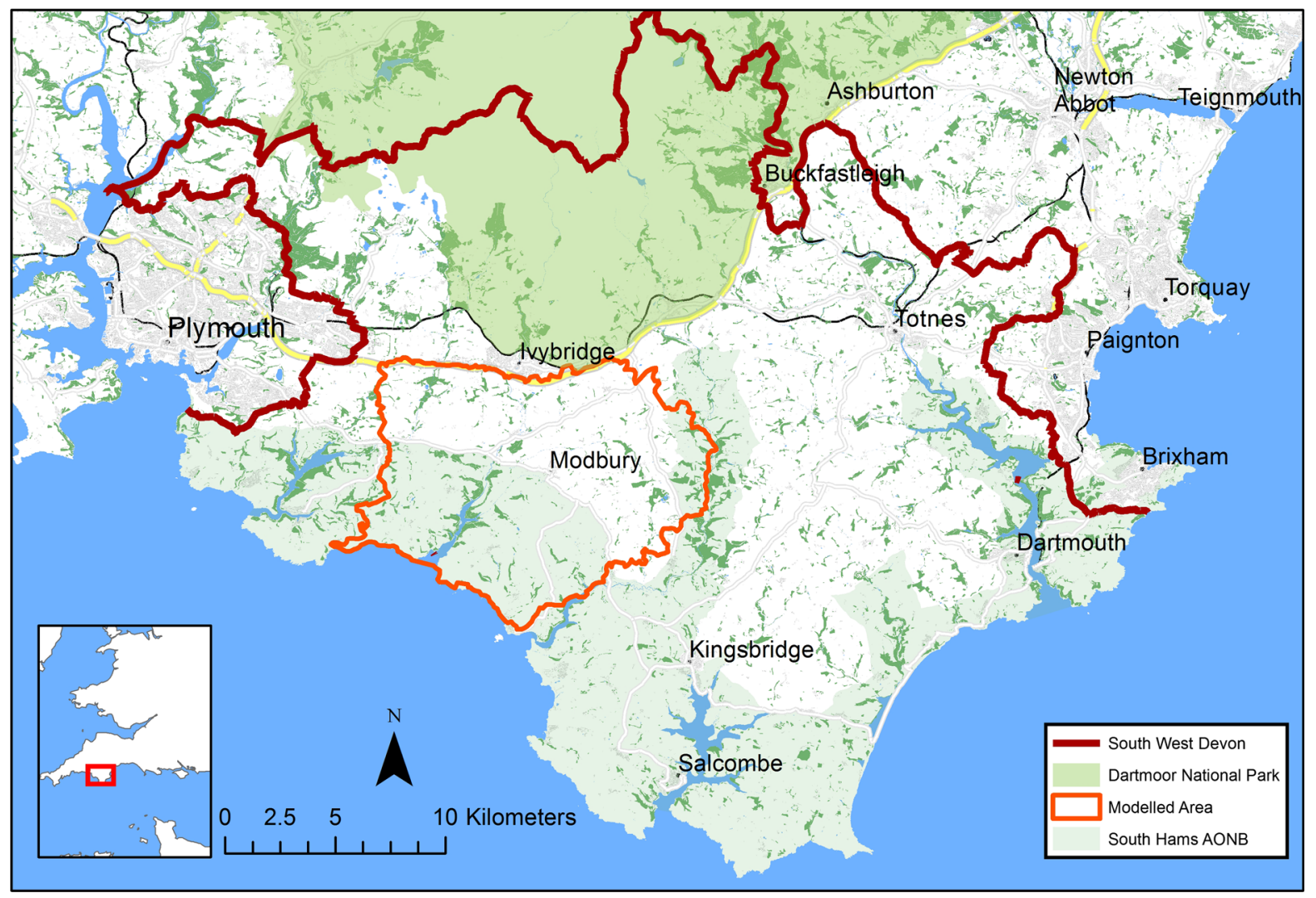

Fig. 1 Study area and location in the United Kingdom 
the UK, AES subsidies are issued by Natural England under the name Countryside Stewardship, and provide financial incentives for land managers to look after the environment. It consists of three levels: higher tier, mid-tier and capital grants. Higher tier covers only the most environmentally significant sites and generally only applies to larger farms. Mid-tier and capital grants are open for all land managers. Higher tier subsidies require stricter environmental management than mid-tier subsidies or individual capital grants (Natural England 2015).

Although Devon has one of the most dense and biodiverse networks of hedgerows in the world, hedgerow density and quality are also declining in Devon (Devon Biodiversity Partnership 2009). Hedgerows are protected by law from being removed and nesting birds must be taken into account by the responsible land manager (Natural England 2015). However, the total lack of management or too frequent cutting lead to deterioration of the quality as a wildlife habitat and the cultural historical value (Sally Hope Johnson, pers. comm. May 14, 2015). Moreover, the shift from traditional hedgerow management practices (i.e. laying and coppicing) towards more mechanized flail cutting has led to taxonomic homogenization of both flora (Staley et al. 2013) and fauna (Facey et al. 2014; Staley et al. 2016). Countryside Stewardship provides subsidies especially targeted at hedgerow management. For instance, land managers can apply for subsidies to limit the frequency of cutting to once every three years, let hedgerows grow taller and hedgerow laying (Natural England 2016). These subsidies are available on all three levels of Countryside Stewardship. However, higher tier applicants often include more and more intensive options such as hedgerow laying, and planting new hedges.

\section{Methods}

Hedgerow quality (measured in cultural value and biodiversity) is dependent on the type of management applied by individual land managers (Staley et al. 2015). Different types of land managers apply different management techniques. However, a land manager who receives AES will adopt the prescribed management instead. The decision to apply for AES is again dependent on the characteristics of the land manager (Morris et al. 2000). Therefore, we sought to explain hedgerow quality by the heterogeneous characteristics of land managers and their attitude towards hedgerows, mediated trough AES.

The methods for this study consist of four distinctive steps (see Fig. 2). First, we identified local dynamics and issues regarding landscape quality and change by desk research, interviewing local stakeholders, and conducting an explorative survey amongst 20 land managers in May 2015. Secondly we translated our findings into an ABM, using NetLogo 5.3, and designed two future scenarios. Thirdly, we conducted a survey to parameterize action rules for the agents in the ABM with actual field data. The two initial scenarios were simulated using the data from the survey. The outcomes were presented in a stakeholder workshop, where stakeholders commented on the model structure and co-designed a third, preferred scenario that we later parameterized into the ABM. In this way the workshop outcomes feed back into redesigning the ABM to make the final outcomes.

\section{Participatory agent-based modeling}

We used ABM to analyze the dynamics of landscape change and explore different future scenarios of the hedgerow density in South West Devon. ABM enables

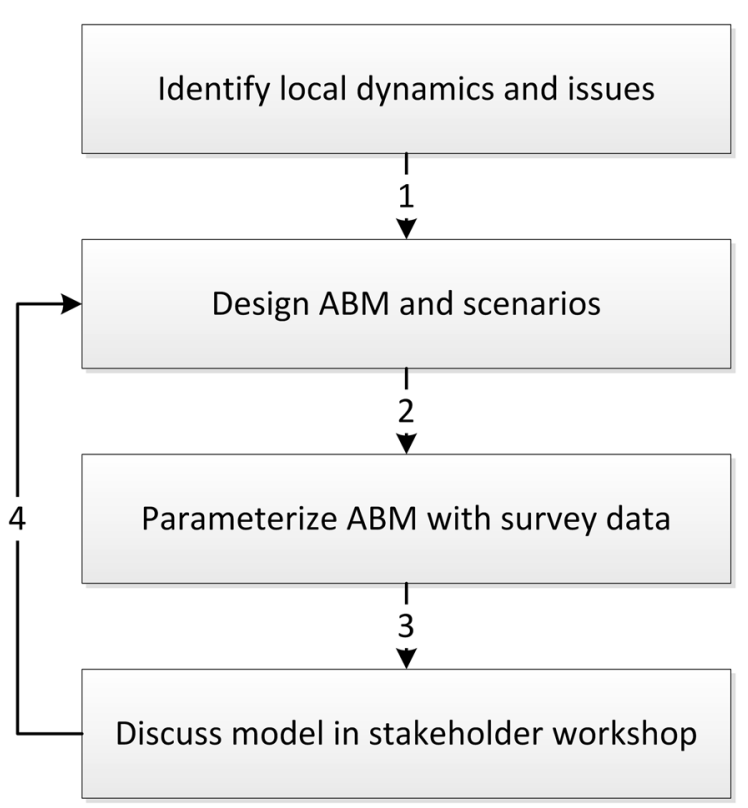

Fig. 2 Four research steps and feedback of workshop outcomes in model structure 
studying the consequences of structural drivers on a spatial environment by creating different action rules for different type of agents in various situations (Valbuena et al. 2010). In an ABM agents perform actions based on predefined rules in a bounded world. To resemble the real world in $\mathrm{ABM}$, parameterization of action rules is preferably made with empirical data, although many applications still rely on stylistic or assumed parameter values (Smajgl et al. 2011).

ABM is pre-eminently a tool that moves away from positivist prediction and prescription, towards a means to facilitate discussion and negotiations. It enables the role of scientific knowledge as clarifying communication, sparking creativity and provoking discussion (Page et al. 2013). We used ABM in a constructivist way: negotiating goals, trade-offs, and how to reach those goals through collective decision-making by exploring possible outcomes with a model of reality (Voinov and Bousquet 2010). Such a constructivist approach requires the active participation of stakeholders outside the academic domain (Mathur et al. 2008).

Nature conservation inherently implies trade-offs to be made between different objectives, such as the conservation of different ecosystem services, local livelihood or biodiversity (McShane et al. 2011). Consequently, it involves multiple societal stakeholders with different interests, each negotiating their claim on natural resources (Giller et al. 2008). We consulted different stakeholders in the earliest phase of the research to co-construct the research question addressing a locally relevant issue (Leach et al. 2002). This both ensures local relevancy, and creates a sense of ownership to the research for local stakeholders, which provides more legitimacy to the project (Rounsevell and Metzger 2010). In a later phase we engaged a wide range of different stakeholders through a dedicated workshop. We used ABM to illustrate our findings, and together with the stakeholders we discussed ways to digest the outcomes and explored policy options to negotiate solutions to possible future issues regarding hedgerow quality.

Input data

Our ABM (available for download at $<$ will be added upon acceptance $>$ ) is designed to include different land manager types relevant to the study area and represents those decision making processes that are expected to influence landscape management, based on expert interviews and a land manager survey. We parameterized our ABM with spatial data to construct the modeled world, and outcomes of a land manager survey to design probability based action rules for the land managers. Additionally we used statistical data regarding land acquisitions to simulate a land market.

To allocate patches of land to land managers we used a cadastral map showing the land registry parcel boundaries of every parcel (Land Registry 2015). Each agent occupied a bundle of connected patches corresponding to one polygon in the cadastral map. We used hedgerow density as a proxy for hedgerow quality. We did not have any data or information on the current state of the hedgerows in the case study area but their location. Hedgerow density, or total length of hedgerows in a given area is more often used as an indicator for the current state of the hedgerows as their disappearance is one of the major threats (Barr and Gillespie 2000; Van der Zanden et al. 2013). The assumed correlation between hedgerow quality and density was supported by the participants at the stakeholder workshop. To assess hedgerow density data we used aerial images from Google Earth and manually digitalized each hedgerow on the modeled area. All spatial data were resampled to a raster with patches of one hectare.

A survey was conducted with 75 face-to-face administered questionnaires in South West Devon in April-May 2016. Respondents were found by systematically driving through South West Devon and knocking on every farm house door without prior notice to conduct an interview of $15 \mathrm{~min}$. This strategy aimed to reduce the potential of selection bias which can occur when using address lists from the internet or the Yellow Pages (Morris et al. 2000). To increase the sample size we also conducted $30 \%$ of the interviews at livestock markets and farm supply stores. We only interviewed individuals that owned or rented a farm of at least one hectare and thus can be considered a land manager; the response-rate was $30 \%$.

With the survey we categorized land managers, identified their attitudes towards hedgerows and subsidies and the impact of their management style on the hedgerow quality. We adopted four types of land managers that were identified to represent the variation in understanding of landscape stewardship (Raymond et al. 2016): (1) character-oriented, (2) aesthetics-oriented, (3) production-oriented, and (4) 
environment-oriented. We asked the land managers to rank eight landscape functions with regard to their importance and categorized land managers based on this ranking. The landscape functions considered are aesthetics, rural tranquility, Devon character, healthy ecosystems, biodiversity, family tradition, generating personal income and food production. Character oriented land managers are identified by a high score on the landscape functions family tradition and Devon character; aesthetic oriented land managers were those with a high score on the aesthetic and rural tranquility landscape functions; environment oriented land managers ranked biodiversity and healthy ecosystems as the most important while production oriented farmers gave priority to food production and generating personal income. The attitude towards hedgerows was identified by a 5-item Likert scale. We also asked land managers if they were enrolled in AES for hedgerow management and what their attitude was regarding AES. The impact of management on the hedgerow quality was identified by scoring the answers to the open question: How do you manage your hedgerows? Answers ranged from mentioning annual mechanized cutting to detailed description of traditional techniques applied. We scored the answers with help from experts and validated this during the stakeholder workshop. A score of one was given for mechanized annual cutting, decreasing the quality of the hedgerow. Three or five year rotational cutting answers were scored with a two, traditional management techniques such as hedge laying and other options for environmentally sensitive management including rejuvenation received three points.

\section{Model setup}

At the model setup each agent is assigned a plot from the land registry map (1117 in total) consisting of a bundle of patches. Each patch, corresponding to a pixel of one hectare, has an initial hedgerow quality that is based on the hedgerow density (see "Input data").

Agents are assigned a set of attributes that determine their actions throughout the model. Based on farm size and agent type, agents are assigned five attributes that determine their 'strategy': (1) likeliness to expand or reduce their farm area, (2) probability to be in an AES at the beginning of the modeling, (3) probability to join an AES during the course of the model run, (4) probability to stay in AES, and (5) an index for a land manager's hedgerow management (Full explanation in supplementary material) (Table 1). Actions of agents throughout the model are based on these strategy attributes of each agent. Some strategy attributes can change when either one of the defining attributes change during the model run.

Moreover, each agent has an initial age (Table 1). This age will logically increase by one year every time step until the agent reaches his deceasing or retirement age (Table 1). Agents who deceased or retired have a probability of having a successor (probability per land manager type from survey). A successor will replace its predecessor and will be assigned a new age and land manager type. Agents without a successor will be removed from the modeled world (See Table 1 for attributes of agents). Below we will describe each action in detail.

\section{Model procedures}

The ABM simulates 30 one-year time steps where agents perform three consecutive actions each time step: (1) buy or sell land from other agents or consolidate their farm size; (2) join, leave, stay in or stay out of AES programs and (3) manage the hedgerows in the land they own (see Fig. 3). The final outcome of the model after 30 years is expressed in an index of hedgerow quality. This mean hedgerow quality index (HQI) is calculated by the mean hedgerow quality of all parcels in the modeled area.

\section{Land market}

Each time step, all agents first determine their land market strategy: to buy, to sell or to consolidate. Each of the three decisions has a predefined probability, which is compared with a random number to define if the land manager buys, sells, or consolidates (see supplementary material for details) (Valbuena et al. 2010). Agents who deceased, or retired without successor, will put all their land for sale before they are removed from the model.

After all agents have established a land market strategy, agents will buy patches from neighboring agents that adopted a selling strategy, starting with the buyer with the highest farm size to the one with the smallest farm. Agents who adopted a buying strategy will buy land until they have reached a predefined 
Table 1 Attributes of agents in the ABM

\begin{tabular}{|c|c|c|c|c|c|}
\hline & Attribute & Options & How it is determined & Probability function & $\begin{array}{l}\text { Value } \\
\text { changes }\end{array}$ \\
\hline \multirow[t]{2}{*}{$\begin{array}{l}\text { Defining } \\
\text { attributes }\end{array}$} & Land manager type & $\begin{array}{l}\text { Environment/aesthetic/ } \\
\text { character/production }\end{array}$ & $\begin{array}{l}\text { Each option has a fixed } \\
\text { probability }\end{array}$ & $\begin{array}{l}\text { Farm size (from } \\
\text { survey) }\end{array}$ & $\begin{array}{l}\text { Each time- } \\
\text { step (year) }\end{array}$ \\
\hline & Farm size & $\geq 1$ ha & $\begin{array}{l}\text { Number of patches } \\
\text { associated to land } \\
\text { manager }\end{array}$ & Land registry & $\begin{array}{l}\text { Each time- } \\
\text { step (year) }\end{array}$ \\
\hline \multirow[t]{5}{*}{ Strategy } & Land market strategy & Sell/buy/consolidate & $\begin{array}{l}\text { Each option has a fixed } \\
\text { probability }\end{array}$ & $\begin{array}{l}\text { Farm size (from } \\
\text { survey) }\end{array}$ & $\begin{array}{l}\text { Each time- } \\
\text { step (year) }\end{array}$ \\
\hline & $\begin{array}{l}\text { Probability to be in } \\
\text { AES }\end{array}$ & $\begin{array}{l}\text { Mid-tier/higher tier/not in } \\
\text { AES }\end{array}$ & $\begin{array}{l}\text { Each option has a fixed } \\
\text { probability }\end{array}$ & $\begin{array}{l}\text { Farm size (from } \\
\text { survey) }\end{array}$ & Fixed \\
\hline & $\begin{array}{l}\text { Probability to join } \\
\text { AES }\end{array}$ & $\begin{array}{l}\text { Join Mid-tier/join higher } \\
\text { tier/stay out }\end{array}$ & $\begin{array}{l}\text { Each option has a fixed } \\
\text { probability }\end{array}$ & $\begin{array}{l}\text { Farm size (from } \\
\text { survey) }\end{array}$ & Fixed \\
\hline & $\begin{array}{l}\text { Probability to stay in } \\
\text { AES }\end{array}$ & Stay in/leave & $\begin{array}{l}\text { Each option has a fixed } \\
\text { probability }\end{array}$ & $\begin{array}{l}\text { Farm size (from } \\
\text { survey) }\end{array}$ & Fixed \\
\hline & $\begin{array}{l}\text { Hedgerow } \\
\text { management } \\
\text { probability }\end{array}$ & $\begin{array}{l}\text { Decrease/consolidate/ } \\
\text { increase }\end{array}$ & $\begin{array}{l}\text { Each option has a fixed } \\
\text { probability }\end{array}$ & $\begin{array}{l}\text { Land manager type } \\
\text { (from survey) }\end{array}$ & $\begin{array}{l}\text { Each time- } \\
\text { step (year) }\end{array}$ \\
\hline \multirow[t]{3}{*}{$\begin{array}{l}\text { Other } \\
\text { attributes }\end{array}$} & Age & $X$ & $\begin{array}{l}\text { Normal distr. } \mathrm{M}=55 \text {, } \\
\quad \mathrm{std}=10\end{array}$ & Survey & $\begin{array}{l}+1 \text { each } \\
\text { year }\end{array}$ \\
\hline & Age of dying & $X$ & $\begin{array}{l}\text { Normal distr. } \mathrm{M}=80 \text {, } \\
\mathrm{std}=4\end{array}$ & Census & Fixed \\
\hline & Successor & Yes/no & Dichotomous probability & $\begin{array}{l}\text { Farm size (from } \\
\text { survey) }\end{array}$ & Fixed \\
\hline
\end{tabular}

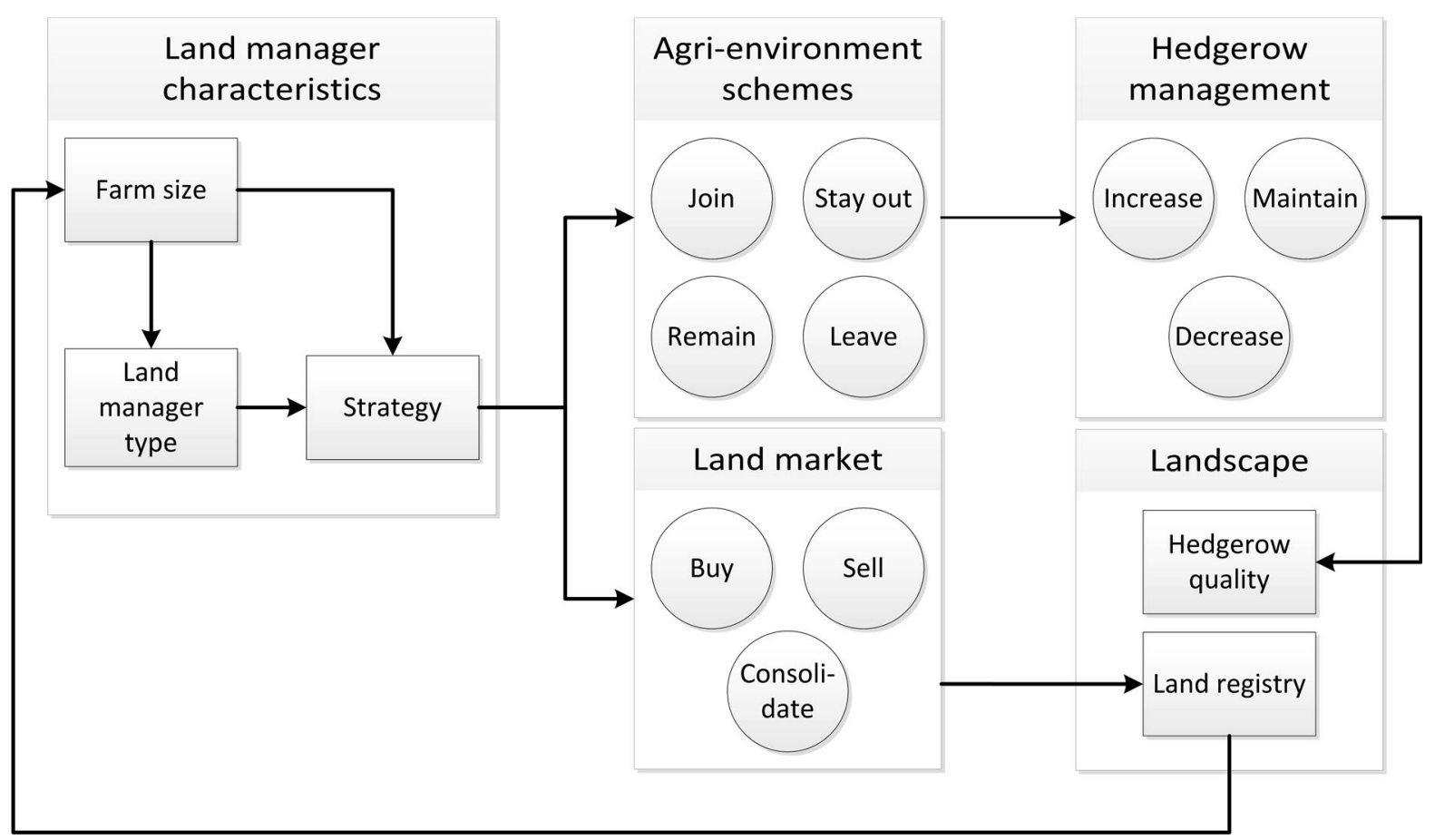

Fig. 3 Action sequence for one time step of the ABM starting from land manager characteristics 
maximum increase of their farmed area (see "Simulation of policy options" section). Likewise, an agent that adopted a selling strategy will stop selling when they reached a maximum number of sold patches. If a buyer has no (more) neighboring selling agents or if they have reached maximum increase, the agent will stop buying this time-step and the next buying agent can start buying. Buying land at $t_{n}$ will decrease the probability of selling at $t_{n+1}$ and vice versa (Valbuena et al. 2010). Buying or selling at $t_{n}$ will increase the probability of consolidating the farm size at $t_{n+1}$.

\section{Agri-environment schemes}

In the next phase, agents decide whether to join, leave or stay in AES. In the model there are two types of AES: higher tier (which prescribed increase of hedgerow quality) and mid-tier (which prescribed keeping the hedgerow quality stable. Enrolment in AES is always for five years. After five years of AES, agents decide whether to stay or leave the AES according to the probability to stay in AES. Agents who are not in AES can enroll any time step if they have a neighboring agent who is already in AES, as information on AES is often passed through by neighbors and/or friends (Falconer 2000). It is based on the probability to join AES.

\section{Hedgerow management}

In the last phase agents manage the hedgerows on their patches. If the agent is not in AES they will manage their hedgerows according to the management strategy index (increase, decrease or maintain). Agents in mid-tier AES will consolidate the hedgerow quality or increase when their attitude is positive. Agents in higher-tier AES are expected to increase the hedgerow quality of all their patches by $1 \%$. Land managers not in AES with a negative attitude towards hedgerows will decrease the hedgerow quality with $10 \%$. These percentages were discussed and approved in the stakeholder workshop as being realistic. The higher change upon degradation as compared to improvement of the hedgerow quality represent the relative high speed of degradation and the long term involved in improving hedgerow quality through regrowth.
Simulation of policy options

To explore how different policy options influence the landscape, we included adjustable parameters representing land market and conservation policies.

We used a single parameter to simulate land market policy: a maximum annual increase of farm size. This parameter reflects all policies targeted at either promoting or countering the effects of scale enlargement. A high value on this parameter $(0.5)$ means that land managers are allowed to increase their farm size by $50 \%$ each time step. It represents policies that favor, or indirectly promote, scale enlargement and/or intensification. An example of such policy is the shift of the Common Agricultural Policy from production support to income support which led to intensification and scale enlargement in Western Europe (van Zanten et al. 2014). In contrast, a lower value that limits the expansion of farms to $10 \%$ per time step, represents policies that are targeted towards the conservation of smaller scale farms (van Zanten et al. 2014). An example is the bolstering of diversification to attract tourism and recreation (Prager and Freese 2009).

Policy aimed at the conservation of wildlife and cultural value of the landscape mostly runs through European AES (Cooke and Moon 2015).To manipulate the magnitude of AES we introduced an adjustable parameter that multiplies the probability of land managers to join AES during the model run.

Scenarios

To test the consequences of different policies we created two scenarios which show two ends of the adjustable parameters (see Table 2): the conservation scenario, and the liberalization scenario. We used the scenarios to highlight the full range of possible outcomes various policies can have on landscape quality.

In the conservation scenario (CS), the government puts emphasis on the conservation of traditional agriculture and a wildlife friendly environment through policies to support landscape conservation, cultural and ecological landscape services and small agri-businesses. In this scenario, farms can only expand with maximally $10 \%$ of their original size each time step (Table 2). While this sounds like a high number, in practice the expansion is limited as farmers can only make small use of expansion opportunities 
Table 2 Adjustable parameter properties and settings

\begin{tabular}{lllll}
\hline Parameter & Description & Value range & LS setting & CS setting \\
\hline LEV_AES & Multiplier of probability to join AES & $0-9$ & 0.5 & 7 \\
MAX_FARM_INCREASE & Maximum increase of farm per time-step & $0.1-0.5$ & 0.5 & 0.1 \\
\hline
\end{tabular}

when land is offered in the neighborhood. This scenario simulated the commercial viability of smaller farms through for instance diversification which limits the need to sell land to larger holdings (Walford 2001). The popularity of mid-tier and higher tier AES was set to the maximum value for each farm size group.

The liberalization scenario (LS) simulated a more laissez-faire attitude of the government, meaning that there were fewer restrictions on the land market for buying and selling land, while agricultural commodity services are promoted. The maximum annual farm expansion of $50 \%$ should be interpreted as a policy that favors intensive and large-scale agriculture over small-scale diversified farms. Potential consequences such as farm amalgamation, intensification and scale enlargement have led to the reduction of diversity and hedgerows in for instance East Anglia (Stoate et al. 2001, 2009). With the likely forthcoming exit of the UK from the EU, the future of AES is now insecure (Grant 2016). In this scenario AES parameters were set to 0.5 for each land manager category, implying that AES subsidies still existed, but at a much lower level which decreased the popularity of the AES across the board. Both scenarios were run 100 times and results presented are mean results of these 100 runs.

In addition to the two policy scenarios, we performed a sensitivity analysis to test and reveal the association between the two parameters and the hedgerow quality index (HQI) and possible interaction between the two adjustable parameters. To do so, we performed a multiple linear regression with the outcomes of the model for ten different settings of both parameters. We ran the model twice for each combination yielding 1000 model runs $(10 \times 5 \times 2)$. Rather than showing the outcomes of separate input variables, this analysis showed how associations from the survey, translated into the model worked together to give a final outcome of the HQI.

\section{Workshop}

Formal stakeholder engagement happened during a stakeholder workshop on May 5, 2016. During this workshop we used preliminary outcomes of the two scenarios to facilitate a discussion on the future of hedgerow quality. The 15 participants were all local to South West Devon. The group consisted of conservation practitioners, local councilors, environmental advisors, environmental scientists and local farmers (anonymous attendance list in supplementary material II). The workshop consisted of three parts. During the first part we presented the same eight different landscape functions as used in the land manager survey and asked the participants to rank these in accordance to their importance. We summarized the outcomes of this exercise, and through discussion and negotiations we identified the three most important landscape functions, which would be used as policy goals in a follow-up exercise.

During the second part we presented both the model structure as well as preliminary outcomes. During this presentation we validated assumptions made in the model and tested whether model outcomes were perceived as plausible to the stakeholders. The center of gravity of the workshop was placed on the third session. In this session, three breakout groups of stakeholders each formulated an own scenario to realize the landscape goals that were set during the first session. Each scenario was presented by the stakeholders to the entire group. The scenarios proposed by the stakeholders were then discussed in order to formulate relevant policy suggestions that accounted for the previously identified landscape goals and were shared by all stakeholders. A selected scenario, co-designed with the workshop participants, was then parameterized and analyzed in the ABM. 


\section{Results}

Survey

The ranking of landscape functions in the questionnaire enabled the categorization of land managers in four types: environment, production, aesthetic and character oriented land managers. Most land managers in the survey were categorized in the production oriented type: often these land managers are characterized as conventional farmers (Valbuena et al. 2008). Production oriented land managers were represented almost three times more than aesthetic and environment oriented land managers, while the smallest group consisted of those oriented towards character.

Land managers of different types showed significantly different attitudes towards hedgerows, were differently subscribed to AES, and applied different hedgerow management strategies (Table 3). Generally, land managers had a positive attitude towards the presence of hedgerows on their land. On a five-item Likert scale from 1 (very negative) to 5 (very positive), only $7 \%$ of the respondents had an average Likert score below three. Environmental, character, and aesthetically oriented land managers showed a score above four, while production land managers were slightly less positive about hedgerows on their farms. The difference between production land managers and other land managers was significant at $95 \%$ confidence level $(\mathrm{p}=0.043)$. Differences in enrolments to AES were more apparent. More than 50\% of "production" land managers were enrolled in an AES, contrary to only $26 \%$ of "character" land managers.

All attributes were used to explain the differences in hedgerow management strategies of land managers, which were operationalized by the hedgerow management index. The data illustrated that the management of hedgerows could be explained by farm size and land manager type, but this is mediated through the attitude towards hedgerows and the enrolment in AES.

The environment oriented land managers showed the highest hedgerow management scores while the character land managers showed the lowest (Table 3). Based on solely the attitude of land managers towards hedgerows, one would have expected production land managers to have the lowest score. However, through their high level of AES enrolment they score a higher hedgerow management index (Table 4).

Model and scenarios results

The translation of the empirical outcomes of the survey into the ABM allowed the exploration of the influence of subsidy programs and scale enlargement on the hedgerow quality, providing an outlook on potential future developments. The scenario simulations were not meant to provide a prediction, but rather serve as a starting point of discussions with stakeholders to consider the impact of structural changes in the agricultural landscape that deviate from past trends. While initial interviews showed that stakeholders in general did not anticipate important changes to the cultural landscape, the simulations were aimed at confronting the stakeholders with how deviations from the current situation, and composition of the farming population could impact the landscape. After 30 modeled years, the two scenarios show a great difference in both land manager population composition and in hedgerow quality. Figure 4 shows the development of land manager population composition under both scenarios (means of 100 runs for each

Table 3 Attitude, AES enrollment and hedgerow management score of different land manager types

\begin{tabular}{lllrl}
\hline Land manager type & $\begin{array}{l}\text { Management } \\
\text { index }\end{array}$ & $\begin{array}{l}\text { Attitude hedgerows } \\
\text { (mean likert score) }\end{array}$ & $\begin{array}{l}\text { IN mid-tier AES } \\
(\%)\end{array}$ & $\begin{array}{l}\text { IN higher-tier AES } \\
(\%)\end{array}$ \\
\hline Environment $(\mathrm{n}=13)$ & 2.25 & 4.10 & 31 & 8 \\
Character $(\mathrm{n}=8)$ & 1.50 & 4.13 & 13 & 13 \\
Production $(\mathrm{n}=36)$ & 1.69 & 3.85 & 39 & 17 \\
Aesthetic $(\mathrm{n}=12)$ & 2.10 & 4.18 & 42 & 0 \\
Total $(\mathrm{n}=69)$ & 1.82 & 3.99 & 35 & 12 \\
\hline
\end{tabular}


Table 4 Attitude, AES enrollment and hedgerow management index of land managers per farm size

\begin{tabular}{|c|c|c|c|c|}
\hline Farm size & Management index & $\begin{array}{l}\text { Attitude hedgerows } \\
\text { (mean likert score) }\end{array}$ & $\begin{array}{l}\text { IN mid-tier } \\
\text { AES }(\%)\end{array}$ & $\begin{array}{l}\text { IN higher-tier } \\
\text { AES }(\%)\end{array}$ \\
\hline$<6$ ha $(\mathrm{n}=12)$ & 1.94 & 4.19 & 0 & 0 \\
\hline $6-50$ ha $(n=26)$ & 1.79 & 3.97 & 35 & 4 \\
\hline $51-100$ ha $(\mathrm{n}=14)$ & 1.44 & 3.88 & 57 & 0 \\
\hline$>100$ ha $(\mathrm{n}=17)$ & 2.00 & 3.97 & 41 & 41 \\
\hline Total $(\mathrm{n}=69)$ & 1.82 & 3.99 & 35 & 12 \\
\hline
\end{tabular}

Fig. 4 Temporal change of percentage of land belonging to small, medium or large farms in the Conservation and Liberalization scenarios. Mean of 100 model runs per scenario

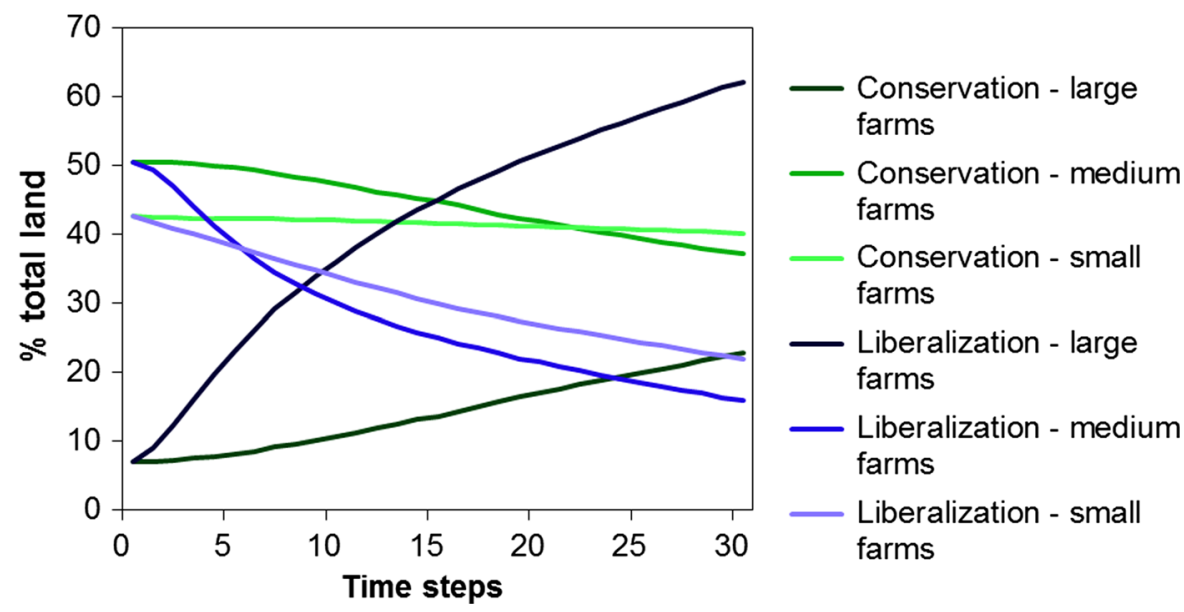

scenario). In the CS, showed in shades of green, the percentage of land belonging to large farms increased from $8 \%$ to over $20 \%$, while land belonging to medium-sized farms and small farms shrunk. In the LS, depicted in shades of blue in Fig. 4, we saw similar patterns, but more extreme. This scenario showed a steady but massive scale enlargement throughout the 30 years. Due to the liberalized land market land managers with large farms were able to increase their farm size drastically at the expense of medium and small sized farms.

The two scenarios show a clear difference in outcome regarding to the hedgerow quality: the LS showed a sharp decrease in hedgerow quality while the CS only showed a minimal decrease (Fig. 5). Spatial patterns of hedgerow quality and changes over time are visualized in Fig. 6. The hedgerow quality in the CS remained largely stable, and spatial patterns of hedgerow quality remained intact over 30 years (Fig. 6c). Some areas show a slight decrease and in some areas the HQI increased. The LS showed an overall decrease (Fig. 6d). Especially areas where the initial HQI was higher showed a decrease (e.g. southwest of Modbury). This resulted in a lower but more evenly spread of hedgerow quality in the area. In both scenarios there are a number of enclaves of about 1 ha where HQI increases. These enclaves represent small farms where environmental oriented land managers managed applied hedgerow friendly management regardless of AES.

Sensitivity analysis

We tested a multiple linear regression model to investigate the associations between the adjustable parameters scale enlargement (MAX_FARM_INCREASE) and AES (multiplier of the probability to join AES, LEV_AES), and the resulting HQI. We computed the interaction term between the two predictors and entered the three variables into the regression model predicting the mean hedgerow quality of the model after 30 years. The outcomes of 
Fig. 5 Temporal change of the mean hedgerow quality index (HQI) in the Conservation and Liberalization scenarios, with or without the wood fuel option. Mean of 100 model runs per scenario

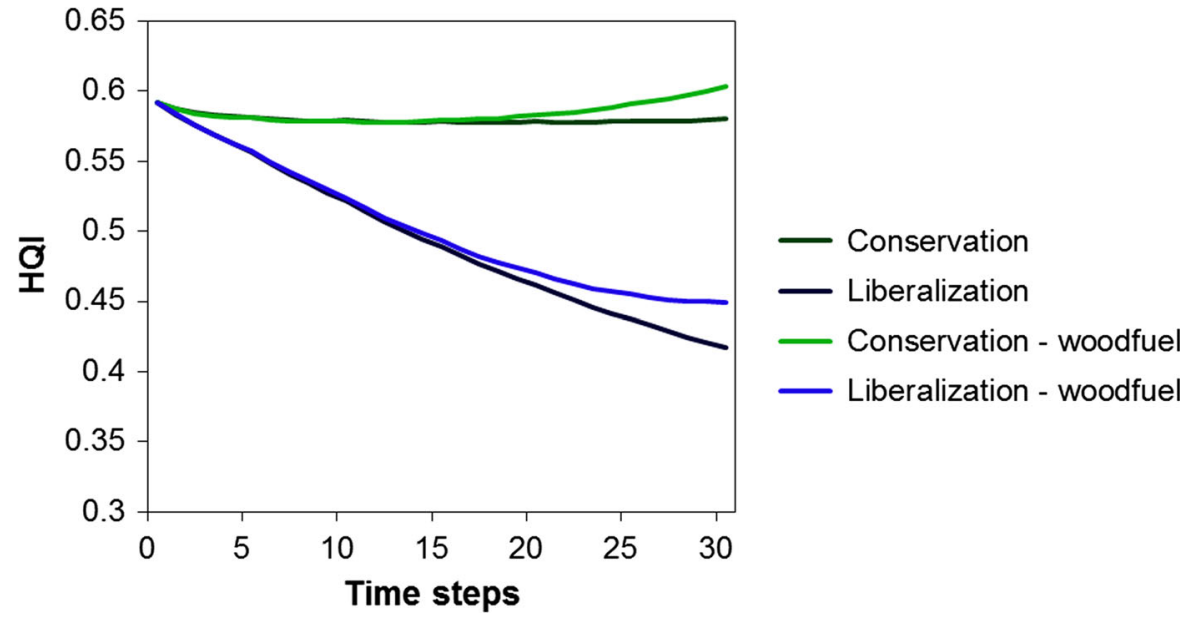

(A) Conservation - hedgerow quality index

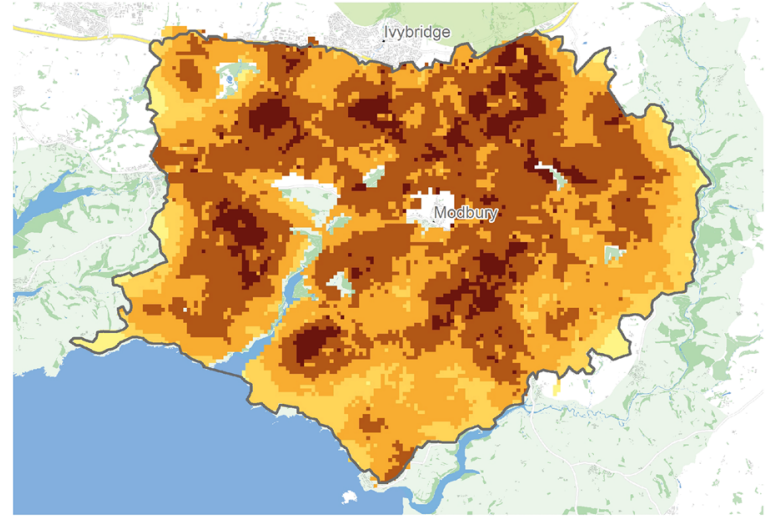

(B) Liberalization - hedgerow quality index

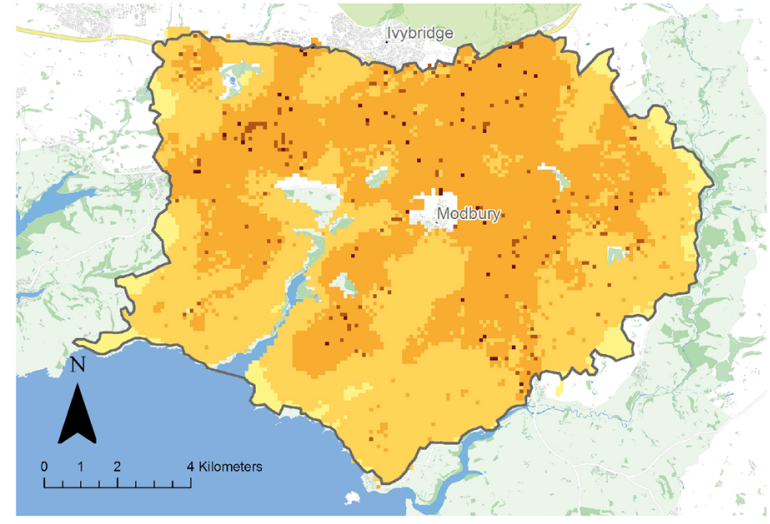

$0-0.2 \square 0.2-0.4 \square 0.4-0.6 \square 0.6-0.8 \square 0.8-1$
(C) Conservation - hedgerow quality index change

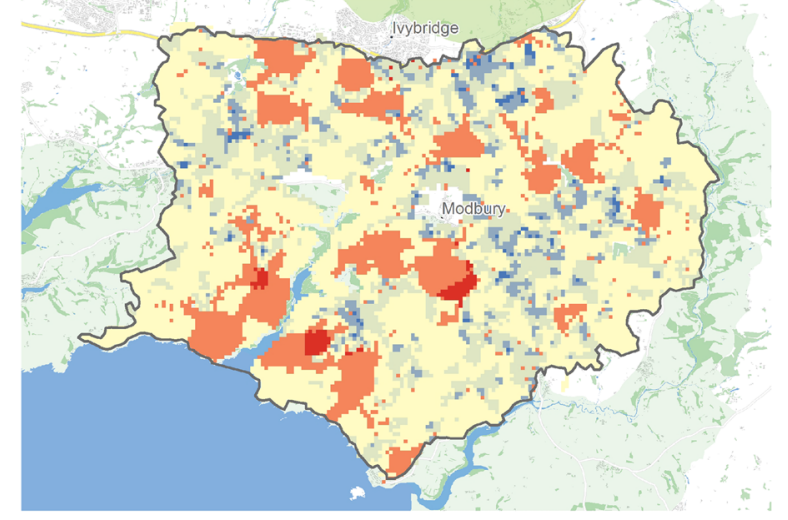

(D) Liberalization - hedgerow quality index change

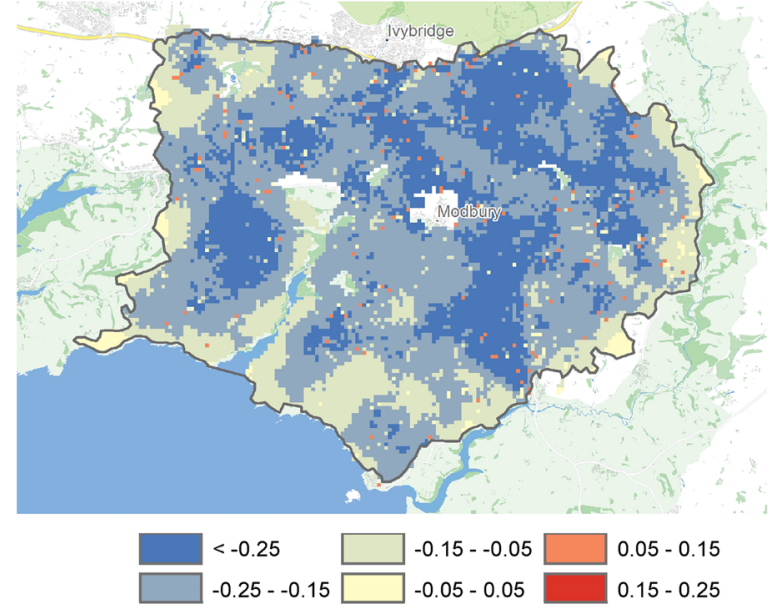

Fig. 6 Spatial patterns of hedgerow quality in conservation and liberalization scenarios (a and $\mathbf{b})$, and changes relative to base year (c and d) 
the model indicate that higher LEV_AES was associated with higher mean HQI while higher MAX_FARM_INCREASE was associated with lower HQI (Table 5). The interaction between the two predictors was also significant (Table 5), suggesting that the association between MAX_FARM_INCREASE and HQI depended on LEV_AES. We estimated a regression model for nine different values of LEV_AES with four different values between zero and one (decrease of AES from current situation) and five above one (increase in AES from current situation). The outcomes of this series of analyses (Table 6) suggested that a low value of LEV_AES revealed a negative association between MAX_FARM_INCREASE and HQI while a higher value yielded a positive association. For a value of LEV_AES between 0.8 and 1 there was no significant association between HQI and MAX_FARM_INCREASE.

\section{Workshop}

The results of the exercise where stakeholders ranked different landscape functions revealed a consensus amongst most stakeholders that healthy ecosystems with high biodiversity should go hand in hand with food production. Conservation of healthy ecosystems and biodiversity were seen as among the most valuable landscape functions of South West Devon by the stakeholders. However, as one stakeholder noted during the workshop, "the South Hams Area of Outstanding Natural Beauty is rather an Area of Outstanding Agricultural Beauty". All stakeholders agreed that conservation programs such as AES are indispensable for a sustainable future of the area, but should always favor an environment for economically viable agriculture. Land managers who were asked to rank landscape functions during the survey, showed more balanced preferences for the eight different landscape functions, with a slightly higher ranking for food production, personal income and family tradition. The largest difference between land managers and workshop participants was found for family tradition; it is ranked as the second most important landscape function for land managers while it was ranked as the least important by stakeholders at the workshop (Fig. 7).

\section{Validity of model results}

Changes in farm size composition and HQI for both scenarios were presented to the workshop audience. Strikingly both scenarios, which showed opposing results, were received as plausible futures for the hedgerow quality of South West Devon. The LS was received as a "doom scenario" as it would eventually lead to a strong decrease of hedgerows in South West Devon in the long run. The stakeholders agreed that with limited AES, land managers would be more likely to apply management strategies that do not favor wildlife. The stakeholders agreed that slowly deteriorating hedgerows would lead to the eventual disappearance of hedgerows all together. Although with current AES this scenario would be highly unlikely, some stakeholders considered the LS possible if the UK were to leave the European Union.

The CS was received as being closer to the current situation and was more favored by the stakeholders. It was widely acknowledged that despite policies that favored environmentally sensitive management of hedgerows, the overall hedgerow quality would still decline. The stakeholders suggested two reasons for this: rules that prevent the removal of hedgerows were not hard enough, making it too easy for developers to buy agricultural land for greenfield development and hedgerow removal; and standards made to measure hedgerow quality and adequate management often did

Table 5 Multiple linear regression of mean hedgerow quality after 30 modeled years with interaction model and LEV_AES and MAX_FARM_INCREASE as predictors

\begin{tabular}{|c|c|c|c|c|}
\hline & $\mathrm{B}$ & $\mathrm{SE}_{\mathrm{b}}$ & BETA & SIG. \\
\hline Constant & 0.403 & 0.003 & & 0.000 \\
\hline MAX_FARM_INCREASE & -0.061 & 0.01 & -0.087 & 0.000 \\
\hline LEV_AES & 0.022 & 0.001 & 0.691 & 0.000 \\
\hline MAX_FARM_INCREASE * LEV_AES & 0.026 & 0.003 & 0.282 & 0.000 \\
\hline
\end{tabular}


Table 6 Linear regression of HQI with

MAX_FARM_INCREASE

as predictor for different

values of LEV_AES
Fig. 7 Ranking of landscape functions by participants of workshop and land managers in survey

\begin{tabular}{|c|c|c|c|c|c|}
\hline LEV_AES & Predictor & B & $\mathrm{SE}_{\mathrm{B}}$ & BETA & SIG. \\
\hline \multirow[t]{2}{*}{0} & Constant & 0.368 & 0.005 & & 0.000 \\
\hline & MAX_FARM_INCREASE & -0.115 & 0.014 & -0.628 & 0.000 \\
\hline \multirow[t]{2}{*}{0.2} & Constant & 0.392 & 0.004 & & 0.000 \\
\hline & MAX_FARM_INCREASE & -0.093 & 0.012 & -0.606 & 0.000 \\
\hline \multirow[t]{2}{*}{0.4} & Constant & 0.411 & 0.005 & & 0.000 \\
\hline & MAX_FARM_INCREASE & -0.079 & 0.014 & -0.503 & 0.000 \\
\hline \multirow[t]{2}{*}{0.6} & Constant & 0.422 & 0.004 & & 0.000 \\
\hline & MAX_FARM_INCREASE & -0.047 & 0.012 & -0.362 & 0.000 \\
\hline \multirow[t]{2}{*}{0.8} & Constant & 0.425 & 0.004 & & 0.000 \\
\hline & MAX_FARM_INCREASE & -0.004 & 0.011 & -0.035 & 0.731 \\
\hline \multirow[t]{2}{*}{1} & Constant & 0.44 & 0.004 & & 0.000 \\
\hline & MAX_FARM_INCREASE & -0.002 & 0.011 & -0.021 & 0.834 \\
\hline \multirow[t]{2}{*}{3} & Constant & 0.503 & 0.002 & & 0.000 \\
\hline & MAX_FARM_INCREASE & 0.081 & 0.007 & 0.776 & 0.000 \\
\hline \multirow[t]{2}{*}{5} & Constant & 0.536 & 0.002 & & 0.000 \\
\hline & MAX_FARM_INCREASE & 0.106 & 0.006 & 0.886 & 0.000 \\
\hline \multirow[t]{2}{*}{7} & Constant & 0.561 & 0.002 & & 0.000 \\
\hline & MAX_FARM_INCREASE & 0.118 & 0.005 & 0.926 & 0.000 \\
\hline \multirow[t]{2}{*}{9} & Constant & 0.579 & 0.001 & & 0.000 \\
\hline & MAX_FARM_INCREASE & 0.125 & 0.003 & 0.965 & 0.000 \\
\hline
\end{tabular}

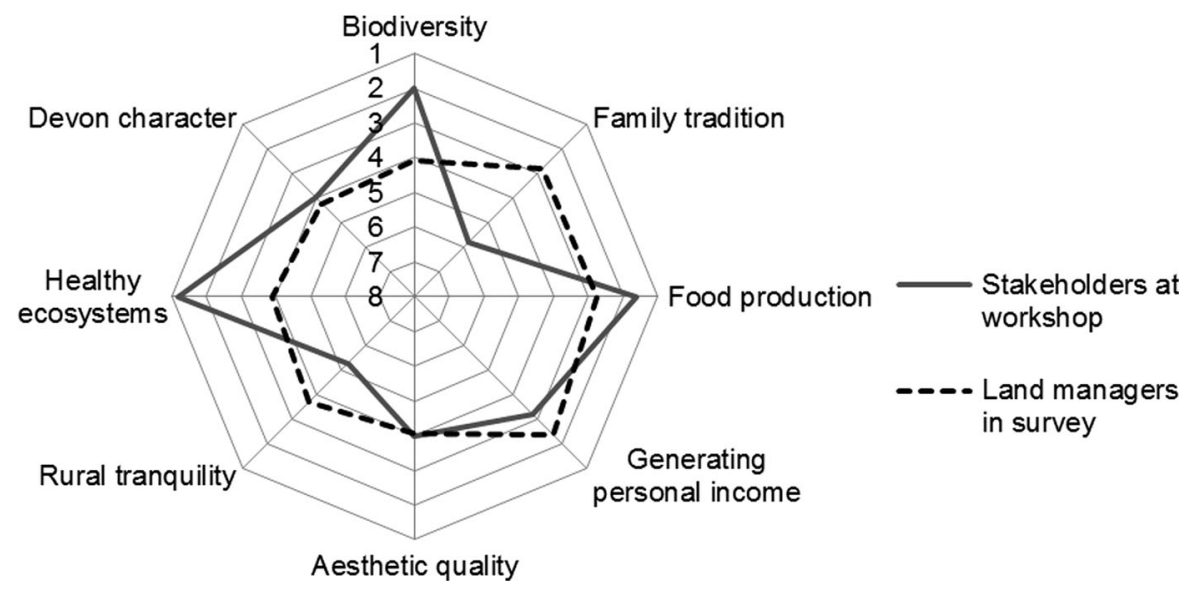

not fit the requirements needed for instance for wildlife to survive. The decline in hedgerow quality even in the CS was therefore seen to resemble reality.

\section{Preferred scenarios by workshop participants}

As a last task the stakeholders were asked to formulate policies or other measures for the next 30 years that would account for the sustainability of the three most important landscape functions named in the earlier exercise. This revealed three main themes where, according to the stakeholders, policy could be improved to retain healthy, biodiverse ecosystems while catering for commercially viable agriculture: revise subsidy schemes, enhance regulation and promote diversification. Some workshop participants suggested that subsidy schemes should be revised for targeted improvement of ecosystems and biodiversity. Primarily, the participants were worried that standards and guidelines in current AES do not provide adequate 
solutions to environmental issues. Moreover, the application process of AES is complicated while the provision of information to land managers is often limited. The second theme emerging from the discussions (Table 7) was that regulations should be better enforced to prevent hedgerow removal or deterioration. A somewhat different theme, but shared amongst all participants was that the economy of South West Devon needs to diversify in order to stay competitive. Solutions provided by stakeholders mostly concerned disseminating the assets of the region in urban areas to attract more tourists and revise tax regulations to tax second home owners more (Table 7).

One policy intervention that all three stakeholder groups mentioned and was directly related to hedgerow quality was wood-fuel harvesting. Currently citizen groups such as the Devon Hedge Group or the Devon Rural Skills Trust are promoting rotational coppicing of hedges to maximize harvesting of wood chips or logs while simultaneously applying a wildlife-friendly management technique. Coppicing is a technique where the hedge is almost entirely harvested. Small stems are left alive; giving the hedge opportunity to rejuvenate in the years after the coppicing takes place. Coppicing will increase the quality of the hedge significantly on the long term in terms of wildlife habitat and is much cheaper and less labor intensive than traditional hedge-laying. However, on the short term coppicing removes the entire hedge which decreases the aesthetic and cultural value of the landscape (Wolton 2014) while leaving very little basal woody material, leading to the loss of shelter for mammals and invertebrates (Staley et al. 2015).

The advantage of coppicing is that it can increase the harvesting of wood chips or logs by over $500 \%$ (Chambers et al. 2015). The wood-fuel option provides a market-driven incentive for land managers to apply more environmentally sensitive management to their hedges without government subsidies (Chambers et al. 2015). Despite the shared enthusiasm among stakeholders at the workshop, actual evidence suggesting that it unequivocally leads to an increase in hedgerow quality is still lacking. Coppicing proved to be advantageous for some (mostly woody plant) species but also less likely to favor shade-tolerant herbaceous flora (Staley et al. 2013).

\section{ABM simulation of wood-fuel scenario}

Although the effects of wood-fuel coppicing are contested and its possible benefits for the environment depend on good practice, the stakeholder workshop agreed that it would be an interesting option for maintaining and enhancing hedgerow quality. Additionally, it seemed practically feasible to simulate the effects of wood-fuel coppicing and therefore we modeled a wood-fuel scenario with the ABM to

Table 7 Policy option suggested by stakeholders at workshop

\begin{tabular}{ll}
\hline Theme & Suggested policy \\
\hline $\begin{array}{l}\text { Revise subsidy } \\
\text { schemes }\end{array}$ & $\begin{array}{l}\text { Provide more assistance and information to land managers for the application process for AES } \\
\text { Revise payment schemes to adapt to local needs rather than apply national standards } \\
\text { Define better standards of landscape goals as current guidelines in AES sometimes do not resemble healthy } \\
\text { ecosystems }\end{array}$ \\
Enhance regulations & $\begin{array}{l}\text { Current planning regulations should be enforced stricter to preserve hedgerows } \\
\text { More controls on pesticide use should prevent further degradation of hedgerows } \\
\text { Attract more tourists to boost the local economy } \\
\text { Tax second homes more, so that affluent second home owners pay fair share for aesthetic enjoyment of the } \\
\text { environment } \\
\text { Attract interest of youth (esp. ethnic minorities) as future generations will be more ethnically mixed } \\
\text { Convince consumer of value of healthy ecosystems to enforce environmentally sensitive management though } \\
\text { consumption } \\
\text { Provide training and education } \\
\text { Promote wood-fuel as incentive for hedgerow management }\end{array}$ \\
\end{tabular}


visualize how grass-root initiatives such as the promotion of wood-fuel harvesting could have an effect on a regional scale. This 'workshop-scenario' was based on the assumption shared by the stakeholders that wood-fuel management indeed increased the hedgerow quality. For the scenario we assumed that each year there was a $50 \%$ probability that one land manager in the entire modeled 'world' adopts woodfuel management. Additionally, each farmer has a probability of $25 \%$ of copying a neighbor that has adopted wood-fuel management (Mena et al. 2011). We modeled this wood-fuel option in both the LS and the CS to explore the results.

The outcomes show an increase of hedgerow quality compared to the non-wood fuel scenarios in both LS and CS (Fig. 5). In LS-WF the decrease of HQI was slightly cushioned compared to the 'normal' LS while the CS-WF shows a slight increase of HQI (Fig. 5). The spatial patterns of the wood-fuel scenarios do not show striking differences compared to the normal scenarios. In CS-WF the increase in some areas, such as south of Modbury (Fig. 8c) is somewhat stronger than in CS. The effect of the wood-fuel scenario becomes stronger as the model progresses and more land-managers adopt the wood-fuel management. The decrease in the HQI in LS-WF becomes less in the last years of the model while the HQI in CSWF begins to increase in the last few years of the model.

\section{Discussion}

In this paper we explored the possibilities of combining ABM with stakeholder engagement to study the effects of scale enlargement and intensification on landscape quality at the local scale. We used a model where driving forces of landscape change influenced the quality of the landscape through the behavior of land managers.

\section{Stakeholder engagement}

The use of ABM in a participatory approach can serve different goals, ranging from the mere communication of study outcomes to relevant stakeholders to an iterative process where model structures and scenarios are co-designed with stakeholders using models as a joint learning tool (Voinov and Bousquet 2010;
Étienne 2011; Voinov et al. 2016). On the more academic side of the spectrum, stakeholder engagement is mainly used as a means to improve the production of scientific knowledge. For example, Van Berkel and Verburg (2012) constructed an ABM of landscape change and used a stakeholder workshop to validate the model with local knowledge and communicate results to the relevant stakeholders. On the other side, ABM can be used to facilitate the design of actual policy or other interventions (Giller et al. 2008). The scientist takes a more passive role and utilizes ABM to illustrate local dynamics while stakeholders can use that "to gain insights through exploration of simulation scenarios that mimic the challenges they face" (Page et al. 2013).

Our attempt to get a better academic understanding of structural driving forces on the quality of the landscape at a regional scale builds closely on the methods of Van Berkel and Verburg (2012). However, we adopted a more constructivist epistemology, by engaging stakeholders in the design of our ABM and trying to model landscape change through discussion and negotiation with local stakeholders at our workshop. The workshop led on the one side to validation of assumptions and outcomes of the ABM and thus an increased academic understanding of the local dynamics of hedgerow quality change. On the other side, it led to the discussion and co-design of preferred future scenarios by stakeholders, which was then modeled in the ABM to check the validity of stakeholder expectations of this scenario.

Early engagement of stakeholders ensured a better discussion and stakeholder involvement in later phases of the research (Voinov and Bousquet 2010), while ABM outcomes provide simple and understandable explorations of possible future scenarios. The landscape function ranking exercise encouraged stakeholders to make trade-offs and interests explicit, stimulating an integrative negotiation process where stakeholders discuss towards a shared solution (Giller et al. 2008). Choices made in a setting such as our workshop are often deliberated and therefore more homogenous (Kenter et al. 2011). The deliberative process of selecting the most important landscape functions led to policy goals shared by all stakeholders. This ensured that during further discussions all stakeholders worked towards the same shared landscape goals. However, other objectives such as the cultural value of landscapes and the associated 
(A) Conservation-WF - hedgerow quality index

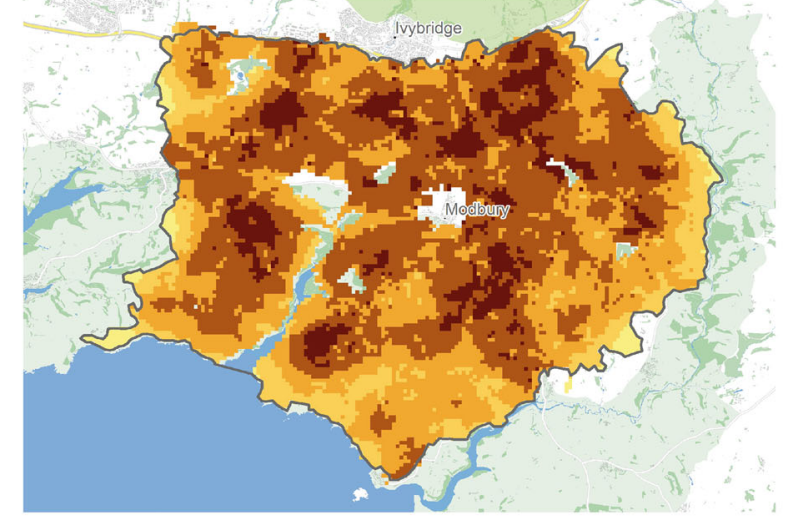

(B) Liberalization-WF - hedgerow quality index

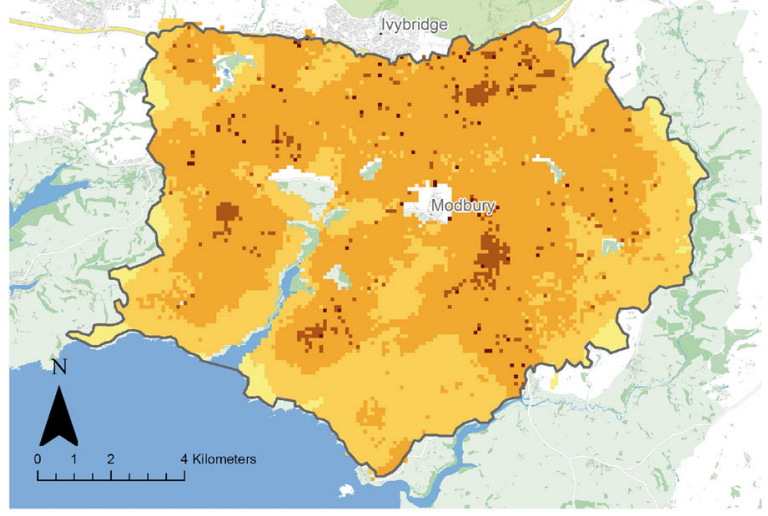

$0-0.2$

$0.2-0.4$

$0.4-0.6$

$0.6-0.8$

$0.8-1$

Fig. 8 Spatial patterns of hedgerow quality in conservation and liberalization scenarios with wood-fuel management (a and b), and changes relative to base year (c and d)

hedgerows (Oreszczyn and Lane 2000) might be valued by stakeholders not present at the workshop and further outcomes could have been biased by the composition of workshop participants.

\section{Modeling results}

The differences in landscape function perception between the workshop participants and land managers during the survey are visible in the outcomes of the two pre-workshop scenarios. Hedgerows form an important part of the cultural heritage of Devon shared by both conservationists as well as farmers (Oreszczyn and Lane 2000). The outcomes of our survey, however, show that generating personal income is more important to land managers than cultural or environmental hedgerow quality. This finding is concurrent
(C) Conservation-WF - hedgerow quality index change

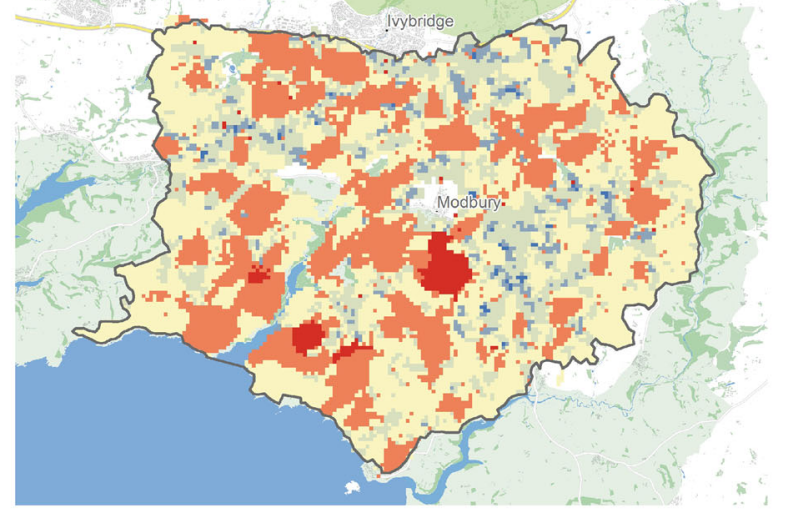

(D) Liberalization-WF - hedgerow quality index change

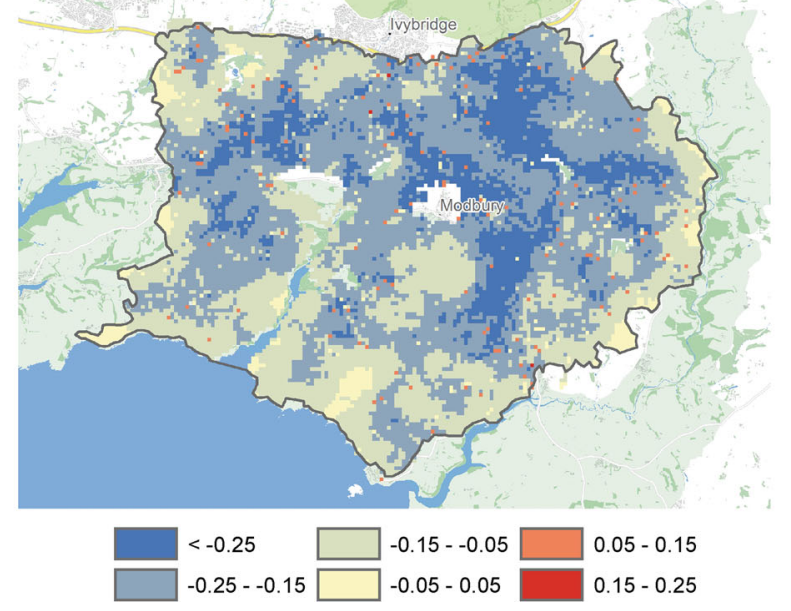

with many other European studies (Ahnström et al. 2008). To trigger land managers to adopt environmentally sensitive management, financial compensation is needed, especially for production oriented farmers. When there are less financial incentives for environmental hedgerow management, as is the case in the Liberalization scenario, land managers will focus on generating personal income rather than focusing on the environment (see also Primdahl et al. 2003). With less AES subsidies hedgerows will likely deteriorate. On the other hand, intensification and scale enlargement will give British farmers a better chance on the global food market to gain personal income. A conservation scenario, which is likely to go hand in hand with higher taxes for the British and more regulations, will provide the financial incentives to land managers to perform hedgerow 
management according to AES standards. However, next to financial considerations land managers might be reluctant in joining AES due to the often high level of bureaucracy (Pavlis et al. 2016). Both the outcomes of the model as well as the participants of the workshop agreed that AES actually lead to increased environmental value of hedgerows.

The sensitivity analysis revealed a strong interaction between the two adjustable parameters in the model. Translated to real world outcomes, the results of the ABM suggest that more scale enlargement would lead to declining hedgerow quality if AES subsidies would be reduced. In contrast, upon increase of AES subsidies, more scale enlargement would lead to an overall increase of hedgerow quality. These opposing results may seem counterintuitive. The mechanism behind this interaction is that land managers with large farms were more likely to apply for AES subsidies than smallholders (Pavlis et al. 2016). If more large holders are enrolled in AES, their expansion will have a positive effect on the hedgerow quality. If they are not enrolled in AES and apply management according to their own attitudes, scale enlargement will have a negative effect. The effect of scale enlargement on hedgerow quality is therefore moderated by the level of AES subsidies. Such counterintuitive results are an important indication of the role of AES in preserving the cultural landscape. While in the literature the role of AES has been contested (Kleijn et al. 2001; de Snoo et al. 2013), the importance for this specific area is clearly indicated. Small hobby farmers with one hectare farms increased the hedgerow quality regardless of AES, but only accounted for a small proportion of the land (Kristensen et al. 2016).

\section{Workshop model}

The discussion resulting from the model presentation and landscape function ranking led to the co-construction of a scenario where natural capital (the wood-fuel potential of hedgerows) and social capital (the willingness of land managers to adopt environmentally sensitive management) is more exploited without demanding for more subsidies. The wood-fuel scenarios show that another incentive aside AES can enhance the conservation of hedgerow quality, even in the liberalization scenario. The scenario was constructed with the assumptions, shared by the stakeholders at the workshop, that rotational coppicing yields actual improvement of hedgerow quality and serious financial gains. More research into the environmental consequences of coppicing is still needed while financial gains from bio energy from coppicing of hedgerows are limited (Gruber and Clauplein 2008). The results of our research show both the willingness of stakeholders to engage in such measures and the potential benefits for the landscape as a whole, warranting the further investigation if the assumed benefits are valid.

\section{Conclusions}

ABM proved to be a very useful tool to communicate outcomes and provide a platform for discussion among a diverse group of stakeholders, leading to an integrative negotiation process where shared problem definitions and solutions were formulated. Explicitly stating landscape goals helped integrating the perspectives of different stakeholders and facilitated a structured discussion for future landscape policy.

Conservation professionals, local policy makers and land managers all agree that the hedgerows of Devon are indispensable to the agricultural landscape. They form key habitat corridors for a sustainable population of various unique species while simultaneously forming the quintessential character of the South West Devon landscape (Natural England 2014). The willingness to conserve these typical features of the Devon landscape was present among the full range of stakeholders. However, without financial incentives land managers will not make the choice to sustain the current hedgerow quality, leading to further deterioration and even disappearance of hedgerows. Scale enlargement can have a positive effect on hedgerow quality if the level of subsidies is high enough land managers of large farms will comply with AES standards. A lower level of AES subsidies might have a very negative effect on the hedgerow quality as land managers with large farms will be less likely to join AES. Harvesting wood fuel from coppiced hedgerows was identified as an alternative measure to add value to hedgerow maintenance and appears, under the assumptions taken, a promising way to incentivize rejuvenating hedgerow management without governmental subsidies. The results warrant further study 
into the environmental consequences of this method (Staley et al. 2015).

Acknowledgements This research was supported by the HERCULES project, funded by the European Commission (Grant 603447, 7th Framework Programme). We would like to thank the participants of the stakeholder workshops for the discussion and suggestions, and Scott Heckbert for his assistance with setting up the agent-based model. We thank two anonymous reviewers whose comments/suggestions helped improve and clarify this manuscript.

Open Access This article is distributed under the terms of the Creative Commons Attribution 4.0 International License (http:// creativecommons.org/licenses/by/4.0/), which permits unrestricted use, distribution, and reproduction in any medium, provided you give appropriate credit to the original author(s) and the source, provide a link to the Creative Commons license, and indicate if changes were made.

\section{References}

Ahnström J, Höckert J, Bergeå HL, Francis CA, Skelton P, Hallgren L (2008) Farmers and nature conservation: what is known about attitudes, context factors and actions affecting conservation? Renew Agric Food Syst 24(1):38-47

Barr CJ, Gillespie MK (2000) Estimating hedgerow length and pattern characteristics in Great Britain using Countryside Survey data. J Environ Manag 60(1):23-32

Carey PD, Wallis S, Chamberlain PM, Cooper A, Emmett BA, Maskell LC, McCann T, Murphy J, Norton LR, Reynolds B, Scott WA, Simpson IC, Smart SM, Ullyett JM (2008) Countryside Survey: UK Results from 2007. NERC/Centre for Ecology \& Hydrology,

Chambers M, Crossland M, Westaway S, Smith J (2015) Harvesting woodfuel from hedges: guidance on bringing England's hedges back into the farm business by managing them for woodfuel. Organic Research Centre, Newbury

Cooke B, Moon K (2015) Aligning 'public good' environmental stewardship with the landscape-scale: Adapting MBIs for private land conservation policy. Ecol Econ 114:152-158

Davies ZG, Pullin AS (2007) Are hedgerows effective corridors between fragments of woodland habitat? An evidencebased approach. Landscape Ecol 22(3):333-351

de Snoo GR, Herzon I, Staats H, Burton RJ, Schindler S, van Dijk J, Lokhorst AM, Bullock JM, Lobley M, Wrbka T, Schwarz G (2013) Toward effective nature conservation on farmland: making farmers matter. Conserv Lett 6(1):66-72

DEFRA (2015) Structure of the agricultural industry in England and the UK at June. https://www.gov.uk/structure-of-theagricultural-industry-survey-notes-and-guidance

Devon Biodiversity Partnership (2009) The nature of Devon-a biodiversity and geodiversity action plan

Devon County Council (2016) Mid-year population estimates. https://new.devon.gov.uk/factsandfigures/data-table/?post $\mathrm{Id}=$ mid-year-population-estimates \& geography $=464$

Étienne M (ed) (2011) Companion modelling. Quae, Versailles
Facey SL, Botham MS, Heard MS, Pywell RF, Staley JT (2014) Moth communities and agri-environment schemes: Examining the effects of hedgerow cutting regime on diversity, abundance, and parasitism. Insect Conserv Divers 7(6):543-552

Falconer K (2000) Farm-level constraints on agri-environmental scheme participation: a transactional perspective. J Rural Stud 16(3):379-394

Fuentes-Montemayor E, Goulson D, Park KJ (2011) The effectiveness of agri-environment schemes for the conservation of farmland moths: assessing the importance of a landscape-scale management approach. J Appl Ecol 48(3):532-542

Fukamachi K, Oku H, Rackham O (2003) A comparative study on trees and hedgerows in Japan and England. In: Palang H, Fry G (eds) Landscape interfaces: cultural heritage in changing landscapes. Springer, Dordrecht, pp 53-69

Giller KE, Leeuwis C, Andersson JA, Andriesse W, Brouwer A, Frost P, Hebinck P, Heitkönig I, van Ittersum M, Koning N, Ruben R (2008) Competing claims on natural resources: what role for science? Ecol Soc 13(2):1-18

Grant W (2016) The challenges facing UK farmers from Brexit. EuroChoices 15(2):11-16

Gruber S, Clauplein W (2008) Wood chips from hedgerowsbiomass potential for on-farm mulching and bioenergy? In: cultivating the future based on science: 2 nd conference of the International Society of Organic Agriculture Research (ISOFAR). Modena, Italy

Hannon LE, Sisk TD (2009) Hedgerows in an agri-natural landscape: potential habitat value for native bees. Biol Conserv 142(10):2140-2154

Hinsley SA, Bellamy PE (2000) The influence of hedge structure, management and landscape context on the value of hedgerows to birds: a review. J Environ Manag 60(1):33-49

Kenter JO, Hyde T, Christie M, Fazey I (2011) The importance of deliberation in valuing ecosystem services in developing countries-evidence from the Solomon Islands. Glob Environ Chang 21(2):505-521

Kleijn D, Berendse F, Smit R, Gilissen N (2001) Agri-environment schemes do not effectively protect biodiversity in Dutch agricultural landscapes. Nature 413(6857):723-725

Kristensen SBP, Busck AG, van der Sluis T, Gaube V (2016) Patterns and drivers of farm-level land use change in selected European rural landscapes. Land Use Policy 57:786-799

Land Registry (2015) Land Registry INSPIRE View Service. https://data.gov.uk/dataset/land-registry-inspire-viewservice-and-metadata.

Leach WD, Pelkey NW, Sabatier PA (2002) Stakeholder partnerships as collaborative policymaking: evaluation criteria applied to watershed management in California and Washington. J Policy Anal Manag 21(4):645-670

Mathur VN, Price ADF, Austin S (2008) Conceptualizing stakeholder engagement in the context of sustainability and its assessment. Constr Manag Econ 26(6):601-609

McShane TO, Hirsch PD, Trung TC, Songorwa AN, Kinzig A, Monteferri B, Mutekanga D, Van Thang H, Dammert JL, Pulgar-Vidal M, Welch-Devine M (2011) Hard choices: making trade-offs between biodiversity conservation and human well-being. Biol Conserv 144(3):966-972 
Mena CF, Walsh SJ, Frizzelle BG, Xiaozheng Y, Malanson GP (2011) Land use change on household farms in the Ecuadorian Amazon: design and implementation of an agent-based model. Appl Geogr 31(1):210-222

Morris J, Mills J, Crawford IM (2000) Promoting farmer uptake of agri-environment schemes: the countryside stewardship arable options scheme. Land Use Policy 17(3):241-254

Natural England (2014) National character area profile: 151 South Devon (NE338). Natural England,

Natural England (2015) Countryside stewardship manual

Natural England (2016) Countryside Stewardship: Hedgerows and Boundaries Grant Manual. Natural England,

Oreszczyn S, Lane A (2000) The meaning of hedgerows in the English landscape: different stakeholder perspectives and the implications for future hedge management. J Environ Manag 60(1):101-118

Page CL, Bazile D, Becu N, Bommel P, Bousquet F, Etienne M, Mathevet R, Souchere V, Trébuil G, Weber J (2013) Agent-based modelling and simulation applied to environmental management. In: Edmonds B, Meyer R (eds) Simulating social complexity: a handbook. Springer, Berlin, pp 499-540

Pavlis ES, Terkenli TS, Kristensen SBP, Busck AG, Cosor GL (2016) Patterns of agri-environmental scheme participation in Europe: indicative trends from selected case studies. Land Use Policy 57:800-812

Plieninger T, Bieling C (2012) Resilience and the cultural landscape: understanding and managing change in humanshaped environments. Cambridge University Press, Cambridge

Plieninger T, Bieling C (2013) Resilience-based perspectives to guiding high nature value farmland through socio-economic change. Ecol Soc 18(4):20

Prager K, Freese J (2009) Stakeholder involvement in agri-environmental policy making-learning from a local- and a state-level approach in Germany. J Environ Manag 90(2):1154-1167

Primdahl J, Peco B, Schramek J, Andersen E, Oñate JJ (2003) Environmental effects of agri-environmental schemes in Western Europe. J Environ Manag 67(2):129-138

Rands MRW (1986) Effect of hedgerow characteristics on partridge breeding densities. J Appl Ecol 23(2):479-487

Raymond CM, Bieling C, Fagerholm N, Martin-Lopez B, Plieninger $\mathrm{T}$ (2016) The farmer as a landscape steward: comparing local understandings of landscape stewardship, landscape values, and land management actions. Ambio 45(2): 173-184

Rounsevell MDA, Metzger MJ (2010) Developing qualitative scenario storylines for environmental change assessment. Wiley Interdiscip Rev Clim Chang 1(4):606-619

Smajgl A, Brown DG, Valbuena D, Huigen MGA (2011) Empirical characterisation of agent behaviours in socioecological systems. Environ Model Softw 26(7):837-844

Staley JT, Amy SR, Adams NP, Chapman RE, Peyton JM, Pywell RF (2015) Re-structuring hedges: rejuvenation management can improve the long term quality of hedgerow habitats for wildlife in the UK. Biol Conserv 186:187-196

Staley JT, Botham MS, Chapman RE, Amy SR, Heard MS, Hulmes L, Savage J, Pywell RF (2016) Little and late: How reduced hedgerow cutting can benefit Lepidoptera. Agric Ecosyst Environ 224:22-28

Staley JT, Bullock JM, Baldock KCR, Redhead JW, Hooftman DA, Button N, Pywell RF (2013) Changes in hedgerow floral diversity over 70 years in an English rural landscape, and the impacts of management. Biol Conserv 167:97-105

Stoate C, Báldi A, Beja P, Boatman ND, Herzon I, Van Doorn A, De Snoo GR, Rakosy L, Ramwell C (2009) Ecological impacts of early 21 st century agricultural change in Europe-a review. J Environ Manag 91(1):22-46

Stoate C, Boatman ND, Borralho RJ, Carvalho CR, Snoo GRd, Eden P (2001) Ecological impacts of arable intensification in Europe. J Environ Manag 63(4):337-365

Tieskens KF, Schulp CJE, Levers C, Lieskovský J, Kuemmerle T, Plieninger T, Verburg PH (2017) Characterizing European cultural landscapes: Accounting for structure, management intensity and value of agricultural and forest landscapes. Land Use Policy 62:29-39

Valbuena D, Verburg PH, Bregt AK (2008) A method to define a typology for agent-based analysis in regional land-use research. Agric Ecosyst Environ 128(1-2):27-36

Valbuena D, Verburg PH, Veldkamp A, Bregt AK, Ligtenberg A (2010) Effects of farmers' decisions on the landscape structure of a Dutch rural region: an agent-based approach. Landsc Urban Plan 97(2):98-110

Van Berkel D, Verburg P (2012) Combining exploratory scenarios and participatory backcasting: using an agent-based model in participatory policy design for a multi-functional landscape. Landscape Ecol 27(5):641-658

Van der Zanden EH, Verburg PH, Mücher CA (2013) Modelling the spatial distribution of linear landscape elements in Europe. Ecol Ind 27:125-136

van Zanten BT, Verburg PH, Espinosa M, Gomez-y-Paloma S, Galimberti G, Kantelhardt J, Kapfer M, Lefebvre M, Manrique R, Piorr A, Raggi M (2014) European agricultural landscapes, common agricultural policy and ecosystem services: a review. Agron Sustain Dev 34(2):309-325

Voinov A, Bousquet F (2010) Modelling with stakeholders. Environ Model Softw 25(11):1268-1281

Voinov A, Kolagani N, McCall MK, Glynn PD, Kragt ME, Ostermann FO, Pierce SA, Ramu P (2016) Modelling with stakeholders-next generation. Environ Model Softw 77:196-220

Walford N (2001) Patterns of development in tourist accommodation enterprises on farms in England and Wales. Appl Geogr 21(4):331-345

Wolton R (2014) Wood fuel from hedges: How to manage and crop hedges in South-West England for Fuel. Devon Hedge Group 